\title{
Temporal dynamics of recovery from extinction shortly after extinction acquisition
}

\author{
Georgina E. Archbold, ${ }^{1,2}$ Nick Dobbek, ${ }^{1}$ and Karim Nader ${ }^{1}$ \\ ${ }^{1}$ Department of Psychology, McGill University, Montreal, Quebec, Canada H3A1B1
}

\begin{abstract}
Evidence suggests that extinction is new learning. Memory acquisition involves both short-term memory (STM) and longterm memory (LTM) components; however, few studies have examined early phases of extinction retention. Retention of auditory fear extinction was examined at various time points. Shortly (1-4 h) after extinction acquisition spontaneous recovery was high compared to that after longer delays $(8-24 \mathrm{~h})$. Recall of a consolidated extinction trace was also impaired if it was preceded $1 \mathrm{~h}$ by extinction of a novel CS; propranolol did not attenuate this effect. These results suggest poor extinction retention reflects a retrieval impairment caused by the aversive experience of extinction training.
\end{abstract}

In Pavlovian fear conditioning pairing a neutral stimulus with an unconditioned aversive stimulus (US) results in conditioned learning, whereby the previously neutral stimulus comes to elicit fear responses. Conversely, the conditioned stimulus (CS) repeatedly presented in the absence of the US leads to reduction of the fear behavior known as extinction (Pavlov 1927). Although there has been some debate over the exact nature of extinction, it is widely accepted that this phenomenon is new learning rather than unlearning of the original association (Rescorla 1997; Bouton 2004). Return of the extinguished behavior is observed in tests of spontaneous recovery (Pavlov 1927), renewal (Bouton and King 1983), and reinstatement (Rescorla and Heth 1975; Bouton and Bolles 1979).

Both behavioral (McGaugh 1966) and molecular (Kandel 2001) studies suggest that following learning there are two distinct phases of memory: short-term memory (STM) and long-term memory (LTM). STM, lasting on the order of minutes to hours, involves covalent modifications of preexisting proteins, while LTM is much less transient and involves protein synthesis, new gene expression, and changes in synaptic structure. Disruption of protein synthesis following learning leads to impairments in LTM retention while sparing STM (Davis and Squire 1984). STM for fear extinction is often considered to be the within-session responding during extinction training, whereas LTM for fear extinction is measured by successful extinction recall usually tested upward of $24 \mathrm{~h}$ (Quirk 2002). Tests of long-term extinction memory are frequently used to measure spontaneous recovery, the return of the original trace that occurs with the passage of time; more recovery is observed with increasing delays between extinction and test (Pavlov 1927; Ellson 1939; Burdick and James 1970; Robbins 1990). Surprisingly, few studies have tested memory for fear extinction within $24 \mathrm{~h}$ of extinction acquisition.

Berman et al. (2003) explored the time course of an extinguished conditioned taste aversion (CTA) memory, testing retention of extinction at intervals as short as $30 \mathrm{~min}$ following extinction. They found that the extinguished behavior was not evident shortly after extinction but became apparent with a delay of $2 \mathrm{~h}$. The authors further determined that the absence of extinction shortly after extinction training was likely due to generation of a short-term aversive trace that blocked the immediate development of extinction. These results are inconsistent with

\section{${ }^{2}$ Corresponding author}

E-mail georgina.archbold@mail.mcgill.ca

Article is online at http://www.learnmem.org/cgi/doi/10.1101//m.028225.112. the idea that recovery of the original memory increases with time. Further, it remains unclear whether extinction of an auditory fear memory will exhibit a similar pattern of recovery. Here we addressed this question and further attempted to determine a mechanism mediating our findings.

Adult male Sprague-Dawley rats (Charles River Laboratories, Quebec) initially weighing 300-325 g, were pair housed in plastic Nalgene cages. They were maintained on a 12-h light/dark cycle (lights on at 7 a.m., off at 7 p.m.) with food and water available ad libitum. All procedures were in accordance with the Canadian Council on Animal Care guidelines and were approved by the McGill University Animal Care and Use Committee. Two conditioning contexts were used: Context A for fear conditioning and Context B for extinction and testing. Varying dimensions, such as shape, illumination, scent, visual and tactile features, and ambient sound, minimized generalization between contexts.

We first determined whether extinction of an auditory fear memory is expressed shortly after extinction acquisition by comparing levels of freezing to a tone at different time points following extinction. Rats were divided into four groups and conditioned using two tone presentations co-terminating with shock (0.8$\mathrm{mA}, 0.5$-sec shock; 5-kHz, 75-dB, 20-sec tone). Three days later all groups received 16 non-reinforced stimulus presentations over $30 \mathrm{~min}$ in Context B. Memory for extinction was tested in Context B 1 h, 4 h, 8 h, or 24 h (Fig. 1A) after extinction training. Extinction produced roughly equivalent within-session reductions in freezing. Figure $1 \mathrm{~B}$ shows that recovery was greater in groups tested $1 \mathrm{~h}$ and $4 \mathrm{~h}$ after extinction than the groups tested at $8 \mathrm{~h}$ and $24 \mathrm{~h}$. A 4 (Group) $\times 2$ (Block) mixed ANOVA comparing the last two-trial block of extinction with the test confirmed a main effect of Group, $F_{(3,45)}=5.41, P<0.05$, and a main effect of Block, $F_{(1,45)}=50.54, P<0.001$. There was also a Group $\times$ Block interaction, $F_{(3,45)}=4.65, P<0.05$, indicating that freezing was higher in groups tested after a short delay. Overall, the results suggest that extinction behavior is absent at short-term time points after extinction acquisition but develops with longer delays between extinction training and test. Consistent with this, in rats that had received two spaced extinction sessions, an extinction-test interval of $2 \mathrm{~min}$ resulted in more recovery of freezing to a feared context than an interval of $24 \mathrm{~h}$ (Morris et al. 2005a).

The transient recovery may reflect a breakdown between phases of memory that support performance (i.e., intermediateterm memory) or a retrieval impairment due to physiological fluctuations produced by the extinction session. In a second experiment we tested whether the absence of extinction behavior was 
A

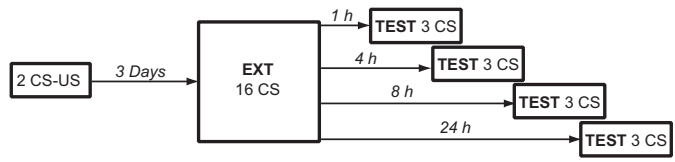

B

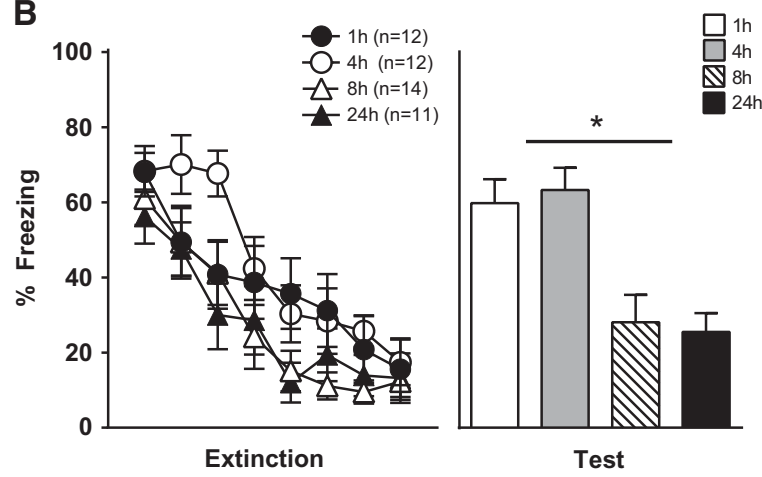

Figure 1. Test for extinction retention at various time points after extinction acquisition. (A) Experimental design. (B) Extinction acquisition. Mean ( \pm SEM) freezing to the tone averaged over two 20-sec stimulus presentations. All animals acquired comparable extinction. Test of extinction memory retention represents mean ( \pm SEM) freezing to the tone averaged over three presentations. Animals were divided into four groups and tested $1 \mathrm{~h}, 4 \mathrm{~h}, 8 \mathrm{~h}$, or $24 \mathrm{~h}$ after extinction acquisition, respectively. Rats in the short-delay groups ( $1 \mathrm{~h}$ and $4 \mathrm{~h}$ ) exhibited high levels of freezing compared to the last block of extinction and to the longer delay testing groups $\left(\left[^{*}\right] P<0.05\right)$.

a specific property of the CS being extinguished or would generalize to other previously extinguished CSs. Animals were fear conditioned to both a tone and a white noise (2-kHz, 75-dB, 20-sec hiss) during separate sessions on consecutive days, the presentation order was counterbalanced such that half the animals received tone as CS1 and white noise as CS2. Both stimuli were then extinguished in separate extinction sessions on successive days. Expression of extinction of CS1 was tested either $1 \mathrm{~h}$ or $24 \mathrm{~h}$ following the extinction of CS2 (i.e., $25 \mathrm{~h}$ or $48 \mathrm{~h}$ after extinction of CS1) (Fig. 2A). At test, $25 \mathrm{~h}$ had elapsed since extinction of CS1 and we might predict that the expression of extinction would be intact; however, the results in Figure 2B demonstrate that this was not the case. Recent extinction of a second CS is sufficient to reinstate responding to a previously extinguished CS. A 2 (Group) $\times 2$ (Block) mixed ANOVA on the last twotrial block of S1 extinction and test session revealed main effects of Group, $F_{(1,23)}=10.20, \quad P<0.05$, and Block, $F_{(1,23)}=8.19, P<0.05$. Importantly, the Group $\times$ Block interaction was also significant, $F_{(1,23)}=5.58, P<0.05$, indicating that there was greater recovery of fear among animals that were tested for freezing to CS1 an hour after extinction of CS2 compared to those tested $24 \mathrm{~h}$ after extinction of CS2.

These results were similar to those of the first experiment: a test given shortly after extinction led to fear recovery. However, in this experiment return of responding to the CS was not a result of a deficit in short-term or intermediateterm extinction memory. Indeed, expres-

A sion of extinction may be impeded by changes in the physiological state of the animal that occur during extinction training.

Adrenergic transmission has been implicated in the formation and persistence of emotional memories (Izquierdo and Medina 1995; Cahill et al. 2000). Similarly, propranolol, a $\beta$-adrenergic receptor antagonist, has been used to reduce fear and anxiety in both humans and rats (Gorman and Dunn 1993; Kent et al. 2002). Morris et al. (2005b) discovered that a brief exposure to a feared context was sufficient to reinstate freezing to an extinguished CS, but only if the exposure occurred 2 min before the $\mathrm{CS}$ test and not $24 \mathrm{~h}$ prior. The reinstatement of freezing following exposure to a feared context appears to be dependent on $\beta$-adrenergic activation as treatment with propranolol attenuated this effect.

In a third experiment we set out to address whether adrenergic activity was mediating the transient recovery from extinction. Behavioral procedures of Experiment 3 were identical to those of Experiment 1; however, 20 min prior to the CS1 retention test, animals were injected intraperitoneally with $5 \mathrm{mg} / \mathrm{kg}$ of propranolol or vehicle (Fig. 3A). All results are shown in Figure 3B. A three-way mixed ANOVA of Test $(1 \mathrm{~h}$ vs. $24 \mathrm{~h}$ ) $\times$ Drug (Prop vs. Veh) $\times$ Block (last extinction vs. test) revealed no main effect of drug or testing time and no interaction between the two. Analysis did indicate a significant main effect of Block, $F_{(3,28)}=19.38, P<0.0001$, and significant interaction of Block $\times$ Test, $F_{(3,28)}=14.10, P<0.001$. Overall, these results indicate that under these conditions treatment with propranolol was unable to prevent the transient recovery observed shortly after extinction.

This is in contrast to previous findings in which propranolol was able to block reinstatement of extinguished fear following exposure to a dangerous context (Morris et al. 2005b). Nonetheless, in these experiments propranolol was given prior to the context exposure which reinstated freezing to an extinguished CS. Consequently, we determined whether propranolol given before extinction was able to block increases in adrenergic activity that might develop during extinction, which would affect the short interval retention test. Examining only the 1-h group, propranolol was injected 20 min prior to extinction acquisition (Fig. 3C). Results indicated no differences between treatment groups as

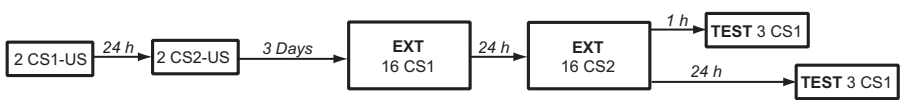

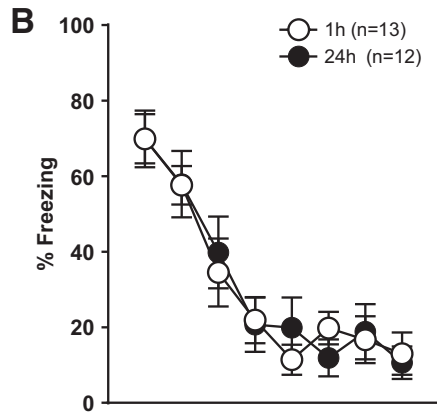

Extinction CS1

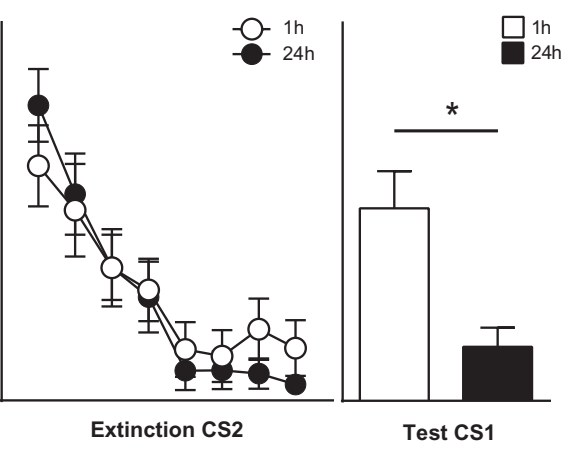

Figure 2. Recent extinction training of a second CS is sufficient to reinstate responding to a previously extinguished CS. ( $A$ ) Experimental design. (B) Extinction acquisition for two conditioned stimuli, CS1 and CS2. Points represent mean $( \pm S E M)$ freezing to the tone averaged over two 20 -sec stimulus presentations. Extinction was comparable between groups for both stimuli. Extinction retention for the first $\mathrm{CS}$ was tested $1 \mathrm{~h}$ or $24 \mathrm{~h}$ after CS2 acquisition. Test represents mean ( \pm SEM) freezing to the tone averaged over three presentations. Animals tested $1 \mathrm{~h}$ after cessation of CS2 extinction exhibited significantly more freezing to CS1 than animals tested $24 \mathrm{~h}$ later $\left(\left[{ }^{*}\right] P<0.05\right)$. 
A

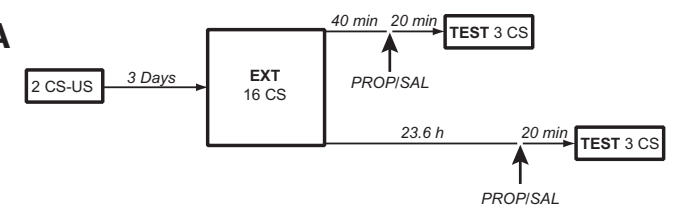

B

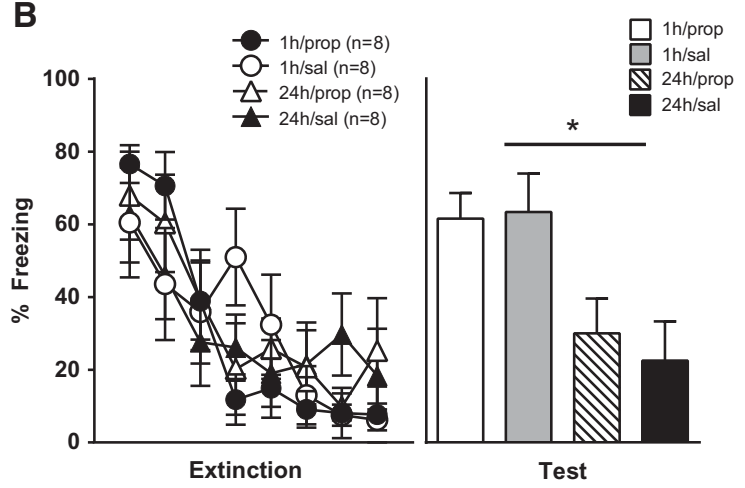

C

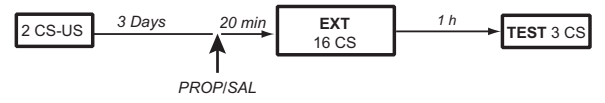

D

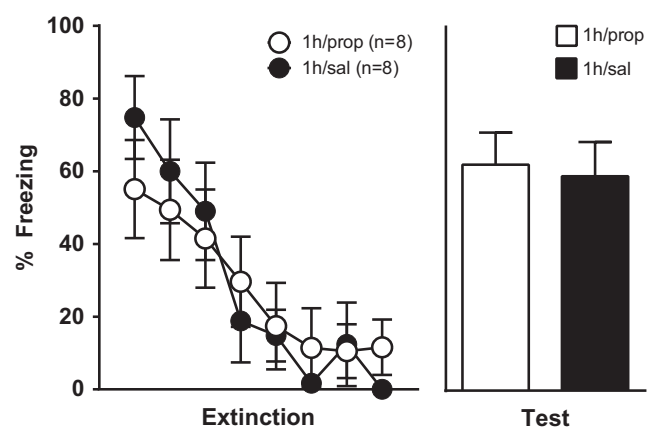

Figure 3. Propranolol does not attenuate the recovery of freezing to the CS tested shortly after extinction. ( $A$ ) Experimental design. (B) Extinction and average test for propranolol treatment $20 \mathrm{~min}$ prior to test. Points represent mean ( \pm SEM) freezing to the tone averaged over two 20 -sec stimulus presentations. Extinction was comparable across all groups. Propranolol was ineffective at reducing recovery of freezing in the 1-h group during the retention test $\left(\left[{ }^{*}\right] P<0.05\right)$. (C) Experimental design. (D) Propranolol given before extinction was unable to prevent recovery of freezing in the $1-\mathrm{h}$ test group.

both groups showed significant recovery during the 1-h retention test after extinction acquisition as indicated by a significant effect of block, $F_{(1,14)}=4.59, P<0.0001$. Even at this time point propranolol was unable to prevent recovery of the original fear conditioning.

The present experiments suggest that memory for auditory fear extinction does not have the same temporal pattern of behavioral expression as predicted by our current understanding of spontaneous recovery. Although significant within-session (short-term) extinction was observed, memory for extinction was absent at 1 -h and 4 -h time points. Good extinction retention was again observed in the 8 -h and 24 -h test groups. This is consistent with the profile of behavior following CTA extinction (Berman et al. 2003) and context fear extinction (Morris et al. 2005a). Generally, the amount of spontaneous recovery is considered a function of the time between extinction and test, such that greater recovery is observed with longer retention intervals. The present results suggest that spontaneous recovery follows a nonmonotonic function that resembles the U-shaped retention curve first described by Kamin (1957).

The "Kamin effect" has been widely demonstrated (Gerber and Menzel 2000; Sutton et al. 2001; Rudy and Wright-Hardesty 2005; McNally et al. 2008). It was initially thought to be a result of two memory systems. One system was responsible for immediate retention, losing strength rapidly after acquisition. A second system, requiring time for consolidation, gradually assumed responsibility for memory retention and expression. Any transient lapse in memory retention was thought to reflect a discontinuity between these two systems. A second interpretation has also been proposed suggesting that the observed lapse in memory is a result of a retrieval impairment due to a discrepancy in the internal state of the animal at intermediate intervals compared to immediate or long-term intervals (Klein and Spear 1970; Klein 1972).

Discontinuous expression of extinction may reflect absence of the memory or the inability to retrieve the extinction memory and respond accordingly. Berman et al. (2003) note that extinction itself may be aversive and lead to hormonal and neurochemical changes that promote reinstatement of fear. Indeed, we found that testing a previously extinguished CS (CS1) $1 \mathrm{~h}$ after extinction of a second CS (CS2) elicited spontaneous recovery. If, how- ever, the CS1 extinction retention test occurred $24 \mathrm{~h}$ after extinction of CS2, there was little recovery. The absence of extinction was not specific to a recently extinguished CS and instead generalized to a previously extinguished CS; thus, the aversive experience of extinction may be sufficient to reinstate freezing to a different previously extinguished CS. These results are consistent with the observations that a recent pre-exposure to a feared context can reinstate extinguished auditory fear memory (Morris et al. 2005a) and exposure to a different malaise associated taste is sufficient to reinstate an extinguished conditioned taste (Berman et al. 2003).

Interestingly, in an appetitive task in which the CS is not an aversive stimulus, memory for extinction is observed $5 \mathrm{~h}$ following extinction training (Brooks and Bouton 1993). Thus, the "lapse" of extinction at a short retention interval may not be a characteristic of all extinction memories. Also contrary to our findings, Quirk (2002) showed that 30 min after extinction of an auditory fear memory, extinction retention was successful. Discrepancies in the results may be due to differences in behavioral protocols or they may indicate that impaired extinction recall does not occur until after $30 \mathrm{~min}$.

It is well established that context can influence responding to a CS after extinction (Bouton et al. 2006). Beyond the modulatory effect of the physical context, there is evidence that the emotional state of the animal can serve as a "context" and lead to the return of the fear responding (Richardson et al. 1984). It has previously been shown that administration of propranolol prior to a brief period spent in a feared context prevents reinstatement of freezing to an extinguished CS that would have otherwise occurred (Morris et al. 2005b). Based on this finding, we hypothesized that the adrenergic system, in response to the aversive experience of being reexposed to the feared CS during extinction, might be mediating the transient spontaneous recovery. Propranolol was administered $20 \mathrm{~min}$ prior to the retention test in both 1 -h and 24-h groups. Additionally, we administered propranolol 20 min prior to the extinction session and then tested for retention at the 1-h time point. Under both conditions propranolol was unable to prevent the transient recovery of freezing observed in the 1-h group. These results suggest that blocking $\beta$-adrenergic activity is unable to attenuate the effects of emotional arousal resulting from the 
recent experience of extinction. This is in contrast to previous findings in which propranolol was able to block reinstatement of extinguished fear following exposure to a dangerous context (Morris et al. 2005b).

The currently established neurocircuitry for fear extinction memories involves the basolateral amygdala (BLA), the central amygdala (CeA), the ventral medial prefrontal cortex (vmPFC), and the hippocampus (HC). The infralimbic cortex (IL) appears to be the critical site in the vmPFC involved in extinction consolidation and retrieval (Laurent and Westbrook 2009; SierraMercado et al. 2011). Inputs to the intercalated (ITC) cells in the amygdala from the IL are also necessary for extinction (Likhtik et al. 2008) and activity in the ITC subsequently suppresses activity in CeA neurons (Quirk et al. 2003; Amano et al. 2010). Given that prelimbic (PL) activity impairs extinction and increases fear expression (Vidal-Gonzalez et al. 2006) while IL activity suppresses fear after extinction (Quirk et al. 2006), it is reasonable to suspect the transient recovery from extinction we observe soon after acquisition may result from disruptions in IL activity and ITC projections to the CeA necessary for fear suppression.

Exposure to stressors results in a number of neurochemical changes within the mPFC. Extinction of eyelid conditioning causes an increase in the extracellular levels of dopamine and noradrenaline in the mPFC that decrease slowly in the $2 \mathrm{~h}$ following (Hugues et al. 2007). Either of these in addition to other neuromodulators may be involved in inhibiting activity in the IL. Further determining the neurochemical changes that accompany IL activation will help elucidate the mechanisms involved in the transient recovery from extinction.

In conclusion, our results suggest that auditory fear extinction is not expressed shortly after extinction training. Poor extinction recall, as measured by spontaneous recovery, follows the nonmonotonic function characteristic of the "Kamin effect." This impairment in retention does not appear to be a result of a storage failure, nor is it mediated solely by $\beta$-adrenergic activity. Understanding the mechanisms and neural circuitry involved in the formation and expression of extinction remains to be fully understood. Future studies directed in this area will likely shed light on the interplay between the expression of fear and the expression of fear extinction and may account for the transient recovery from extinction.

\section{Acknowledgments}

We thank Dr. Andy Baker for his insight and help in this project. This research was supported by grants from the Natural Sciences and Engineering Research Council (NSERC) and Canadian Institute of Health Research (CIHR) to K.N.

\section{References}

Amano T, Unal CT, Paré D. 2010. Synaptic correlates of fear extinction in the amygdala. Nat Neurosci 13: 489-494.

Berman DE, Hazvi S, Stehberg J, Bahar A, Dudai Y. 2003. Conflicting processes in the extinction of conditioned taste aversion: Behavioral and molecular aspects of latency, apparent stagnation, and spontaneous recovery. Learn Mem 10: $16-25$.

Bouton ME. 2004. Context and behavioral processes in extinction. Learn Mem 11: 485-494.

Bouton ME, Bolles RC. 1979. Contextual control of the extinction of conditioned fear. Learn Motiv 10: 445-466.

Bouton ME, King DA. 1983. Contextual control of the extinction of conditioned fear: Tests for associative value of the context. J Exp Psychol Anim Behav Process 9: 248-265.

Bouton ME, Westbrook RF, Corcoran KA, Maren S. 2006. Contextual and temporal modulation of extinction: Behavioral and biological mechanisms. Biol Psychiatry 60: 352-360.

Brooks DC, Bouton ME. 1993. A retrieval cue for extinction attenuates spontaneous recovery. J Exp Psychol Anim Behav Process 19: 77-89.
Burdick CK, James JP. 1970. Spontaneous recovery of conditioned suppression of licking by rats. J Comp Physiol Psychol 72: 467-470.

Cahill L, Pham CA, Setlow B. 2000. Impaired memory consolidation in rats produced with $\beta$-adrenergic blockade. Neurobiol Learn Mem 74: 259-266.

Davis HP, Squire LR. 1984. Protein synthesis and memory: A review. Psychol Bull 96: 518 .

Ellson DG. 1939. Spontaneous recovery of the galvanic skin response as a function of the recovery interval. J Exp Psychol Gen 26: 586-600.

Gerber B, Menzel R. 2000. Contextual modulation of memory consolidation. Learn Mem 7: 151-158.

Gorman AL, Dunn AJ. 1993. $\beta$-Adrenergic receptors are involved in stress-related behavioral changes. Pharmacol Biochem Behav 45: 1-7.

Hugues S, Garcia R, Léna I. 2007. Time course of extracellular catecholamine and glutamate levels in the rat medial prefrontal cortex during and after extinction of conditioned fear. Synapse 61: $933-937$.

Izquierdo I, Medina JH. 1995. Correlation between the pharmacology of long-term potentiation and the pharmacology of memory. Neurobiol Learn Mem 63: 19-32.

Kamin LJ. 1957. The retention of an incompletely learned avoidance response. J Comp Physiol Psychol 50: 457-460.

Kandel ER. 2001. The molecular biology of memory storage: A dialogue between genes and synapses. Science 294: 1030-1038.

Kent JM, Mathew SJ, Gorman JM. 2002. Molecular targets in the treatment of anxiety. Biol Psychiatry 52: 1008-1030.

Klein SB. 1972. Adrenal-pituitary influence in reactivation of avoidance-learning memory in the rat after intermediate intervals. J Comp Physiol Psychol 79: 341-359.

Klein SB, Spear NE. 1970. Forgetting by the rat after intermediate intervals ("Kamin effect") as retrieval failure. J Comp Physiol Psychol 71: 165-170.

Laurent V, Westbrook RF. 2009. Inactivation of the infralimbic but not the prelimbic cortex impairs consolidation and retrieval of fear extinction. Learn Mem 16: 520-529.

Likhtik E, Popa D, Apergis-Schoute J, Fidacaro GA, Paré D. 2008. Amygdala intercalated neurons are required for expression of fear extinction. Nature 454: 642-645.

McGaugh JL. 1966. Time-dependent processes in memory storage. Science 153: $1351-1358$.

McNally GP, Augustyn KA, Richardson R. 2008. GABAA receptors determine the temporal dynamics of memory retention. Learn Mem 15: 106-111.

Morris RW, Furlong TM, Westbrook RF. 2005a. Recent exposure to a dangerous context impairs extinction and reinstates lost fear reactions. J Exp Psychol Anim Behav Process 31: 40-55.

Morris RW, Westbrook RF, Killcross AS. 2005b. Reinstatement of extinguished fear by $\beta$-adrenergic arousal elicited by a conditioned context. Behav Neurosci 119: 1662-1671.

Pavlov IP. 1927. Conditioned reflexes: An investigation of the physiological activity of the cerebral cortex (ed. Anrep GV). Oxford University Press, London.

Quirk GJ. 2002. Memory for extinction of conditioned fear is long-lasting and persists following spontaneous recovery. Learn Mem 9: 402-407.

Quirk GJ, Likhtik E, Pelletier JG, Paré D. 2003. Stimulation of medial prefrontal cortex decreases the responsiveness of central amygdala output neurons. J Neurosci 23: 8800-8807.

Quirk GJ, Garcia R, González-Lima F. 2006. Prefrontal mechanisms in extinction of conditioned fear. Biol Psychiatry 60: 337-343.

Rescorla RA. 1997. Response inhibition in extinction. QJ Exp Psychol B 50: $238-252$.

Rescorla RA, Heth DC. 1975. Reinstatement of fear to an extinguished conditioned stimulus. J Exp Psychol Anim Behav Process 104: 88-96.

Richardson R, Riccio DC, Devine L. 1984. ACTH-induced recovery of extinguished avoidance responding. Physiol Psychol 12: 184-192.

Robbins SJ. 1990. Mechanisms underlying spontaneous recovery in autoshaping. J Exp Psychol Anim Behav Process 16: 235-249.

Rudy JW, Wright-Hardesty K. 2005. The temporal dynamics of retention of a context memory: Something is missing. Learn Mem 12: 172-177.

Sierra-Mercado D Jr, Padilla-Coreano N, Quirk GJ. 2011. Dissociable roles of prelimbic and infralimbic cortices, ventral hippocampus, and basolateral amygdala in the expression and extinction of conditioned fear. Neuropsychopharmacology 36: 529-538.

Sutton MA, Masters SE, Bagnall MW, Carew TJ. 2001. Molecular mechanisms underlying a unique intermediate phase of memory in Aplysia. Neuron 31: 143-154.

Vidal-Gonzalez I, Vidal-Gonzalez B, Rauch SL, Quirk GJ. 2006. Microstimulation reveals opposing influences of prelimbic and infralimbic cortex on the expression of conditioned fear. Learn Mem 13: $728-733$.

Received August 16, 2012; accepted in revised form May 14, 2013. 


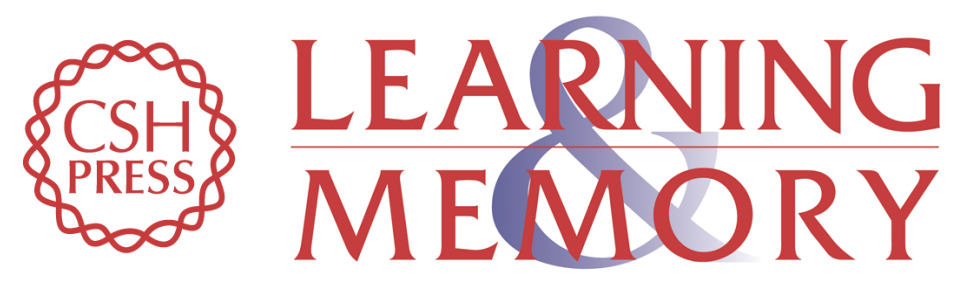

\section{Temporal dynamics of recovery from extinction shortly after extinction acquisition}

Georgina E. Archbold, Nick Dobbek and Karim Nader

Learn. Mem. 2013, 20:

Access the most recent version at doi:10.1101/Im.028225.112

References This article cites 37 articles, 11 of which can be accessed free at: http://learnmem.cshlp.org/content/20/8/395.full.html\#ref-list-1

Creative This article is distributed exclusively by Cold Spring Harbor Laboratory Press for the Commons License first 12 months after the full-issue publication date (see http://learnmem.cshlp.org/site/misc/terms.xhtml). After 12 months, it is available under a Creative Commons License (Attribution-NonCommercial 3.0 Unported), as described at http://creativecommons.org/licenses/by-nc/3.0/.

Email Alerting Receive free email alerts when new articles cite this article - sign up in the box at the Service top right corner of the article or click here. 